\title{
Reflexões sobre experiências de formação continuada de professores em um centro de ciências: trajetória, concepções e práticas formativas
}

\author{
Reflections on teachers' educations in a science center: \\ trajectory, conceptions and formative practices
}

Fernanda Bassoli ${ }^{1}$. José Guilherme S. Lopes² ${ }^{2}$ Eloi Teixeira César ${ }^{3}$

\begin{abstract}
Resumo: Neste artigo são discutidas a trajetória, as práticas formativas e os modelos pedagógicos predominantes nos processos de formação continuada de professores que participaram de cursos oferecidos pelo Centro de Ciências da Universidade Federal de Juiz de Fora no período de 2007 a 2015. Foram utilizados como fonte de dados relatórios enviados aos órgãos de fomento, pesquisas que tiveram tais experiências como objeto de investigação e registros dos professores formadores. Como suporte teórico para as análises, os seguintes modelos de formação subsidiaram o estudo: modelo clássico; prático reflexivo e emancipatório-político. Destaca-se que esses modelos constituíram um importante referencial para a análise e reflexão das práticas formativas desenvolvidas. Assim, são apresentados indicativos de mudanças na concepção dos projetos de formação continuada ao longo dos dez últimos anos, deslocando-se do modelo formativo clássico em direção ao modelo emancipatório-político, cujo debate tem relevância para a formação docente.
\end{abstract}

Palavras-chave: Formação continuada de professores. Ensino de ciências. Modelo de formação docente.

\begin{abstract}
In the present article we describe the trajectory, formative practices and pedagogical models most frequently employed in teachers' continuing education experiences at the Sciences Center of the Federal University of Juiz de Fora between 2007 and 2015. As data sources, we have used reports made to financial support agencies, research that was conducted with the mentioned courses as an object of study and notes and observations from mediators. As theoretical support for the analysis we have used the formation models: (i) classical; (ii) reflexive practical; and (iii) political-emancipatory. We emphasize that these models are an important reference for the analysis and reflection on the training practices that we have been developing offering support to promote changes in the design of continuing education projects and the trajectory of the same, moving from the classical training model towards the emancipatory-political model. This discussion is of great relevance to the current debate on teacher education.
\end{abstract}

Keywords: Continuing teacher education. Science Teaching. Teacher education models.

\footnotetext{
${ }^{1}$ Universidade Federal de Juiz de Fora (UFJF), Colégio de Aplicação João XXIII, Departamento de Ciências Naturais, Juiz de Fora, MG, Brasil. E-mail: <fernanda.bassoli@ufjf.edu.br>.

${ }^{2}$ UFJF, Departamento de Química, Juiz de Fora, MG, Brasil.

${ }^{3}$ UFJF, Centro de Ciências, Juiz de Fora, MG, Brasil.
} 


\section{Introdução}

Atualmente, as pesquisas realizadas na área de formação de professores, em uma perspectiva de formação crítico-reflexiva têm destacado a importância: do desenvolvimento da autonomia docente (ALARCÃO, 2011; DINIZ-PEREIRA; ZEICHNER, 2011; ELLIOT, 2010; MARCELO, 1999; NÓVOA, 2007); da valorização da história de vida (NÓVOA, 2007); dos saberes dos professores (SHULMAN, 1986; TARDIF, 2010); da dialeticidade entre teoria e prática (KEMMIS; WILKINSON, 2011); da valorização da escola como espaço privilegiado para a formação docente, por meio da constituição de grupos colaborativos de professores em parceria com as universidades (ELLIOT, 2010; IBIAPINA, 2008; MALDANER, 2006; PIMENTA, 2005); da associação entre ensino e pesquisa, contribuindo para a formação do professor-pesquisador (IBIAPINA, 2008; MALDANER, 2006; ZEICHNER, 1993); e, do fomento à reflexão crítica sobre a prática, promovendo uma aproximação com as pesquisas e referenciais teóricos da educação (DINIZ-PEREIRA; ZEICHNER, 2011; SMYTH, 1991; ZEICHNER, 1993).

Apesar dos avanços conquistados a partir dos referidos programas de pesquisa desenvolvidos nas duas últimas décadas, a formação dos professores tem se mantido como um grande desafio para o desenvolvimento de políticas públicas e renovação de práticas formativas nas instituições responsáveis pela formação (GATTI, 2009). Há uma vasta literatura que permite identificar diferentes modelos ${ }^{4}$ de formação já consolidados e praticados no Brasil ao longo de décadas (AZEVEDO et al., 2012; CANDAU, 1982, 1997; CUNHA, 2013; DAMIS, 2003; OLIVEIRA, 2011; PALMA FILHO; ALVES, 2003; PEREIRA, 2000; SAVIANI, 2009). Tais estudos apontam que as políticas e práticas relativas à formação docente sofreram influência direta de diversas concepções teórico-metodológicas ao longo da história, refletindo nas pesquisas educacionais (CUNHA, 2013).

$\mathrm{Na}$ área de Educação em Ciências, as pesquisas voltadas para a educação em museus e centros de ciências têm crescido de forma intensa nos últimos anos (BIZERRA, 2009; OVIGLI, 2013). Ovigli (2013), ao realizar uma revisão bibliográfica sobre o tema verificou que os focos temáticos dos estudos concentram-se em "programas, ações e exposições", na "aprendizagem" e na "formação de professores". Apesar de a formação docente configurar entre os temas mais investigados, congregando pesquisas que abordam desde a formação inicial à continuada para utilização didático-pedagógica dos museus de ciências, como também programas e ações educativas diversificados, poucas pesquisas têm sido realizadas sobre a formação continuada de professores nesses espaços, de modo que segundo Jacobucci, Jacobucci e Negid-Neto (2009, p. 119) "[...] a literatura na área ainda é muito escassa no país, com relatos isolados de atividades em um ou outro centro ou museu de ciências”. Igualmente são raros os estudos que analisam criticamente as ações de formação continuada desenvolvidas nesses espaços, bem como suas contribuições para o desenvolvimento profissional dos docentes (JACOBUCCI, 2006; PAULA et al., 2014; PEREIRA, 2014; SILVA, 2013).

\footnotetext{
${ }^{4}$ A palavra modelo está sendo aqui utilizada como "conjunto de características que descrevem e explicam um determinado sistema passível de reprodução. Os diversos modelos pedagógicos aceitos atualmente reúnem concepções diferenciadas de Homem, de professor, de formação, de escola, de mundo, as quais são evidenciadas pelas características das políticas e das ações geradas pelos mesmos” (JACOBUCCI, 2006, p. 30).
} 
Embora reconheçamos que esses espaços apresentam especificidades, entendemos que os processos de formação de professores que neles ocorrem - em termos de modelos e racionalidades -, compartilham as mesmas questões do campo de pesquisa sobre formação docente. Assim, concordamos com Gouvêa et al. (2001) que tais especificidades podem representar potencialidades, uma vez que os centros de ciências são espaços favoráveis para aguçar a percepção, a curiosidade e promover interações entre pessoas, além de estimularem o comportamento investigativo.

Segundo Silva e Bastos (2012) a análise e a avaliação das políticas e das ações de formação continuada, por meio de pesquisas científicas, são imprescindíveis para não serem replicados conteúdos e modelos de ensino desconectados das necessidades dos professores e de seu contexto de atuação profissional. Portanto, é fundamental que tais ações sejam acompanhadas de uma constante reflexão crítica por parte dos formadores. Entendemos assim, que os modelos teóricos vão muito além de uma tendência academicista de formalização, fornecendo elementos para reflexão (e avaliação) sobre "onde estamos" e para "onde queremos ir".

Nesta direção, ao realizarmos um processo de (re)avaliação e reflexão acerca das práticas voltadas à formação continuada que vínhamos desenvolvendo no Centro de Ciências da Universidade Federal de Juiz de Fora (UFJF) tivemos acesso ao trabalho de Jacobucci (2006), que nos impulsionou a reelaborá-las em suas bases teórico-epistemológicas. Assim, o objetivo deste estudo foi analisar as propostas de formação de professores e os modelos formativos norteadores dessas ações em centros e museus de ciências brasileiros, o que nos motivou a fazer uma análise das ações de formação continuada de professores de ciências oferecidas desde 2007 pelo Centro de Ciências da UFJF, com base nesses modelos, que serão apresentados a seguir.

\section{Concepções e modelos de formação de professores}

A partir de sua pesquisa, Jacobucci (2006) delimitou três principais concepções de formação docente: (a) positivista: com alusão ao paradigma da racionalidade técnica; (b) interpretativa: com referência à epistemologia da prática; e, (c) crítico-dialética: baseada na perspectiva sócio-histórica. Com base nessas concepções, sistematizou três modelos formativos: (i) clássico; (ii) prático-reflexivo; e (iii) emancipatório-político, os quais descrevemos abaixo e sintetizamos no Quadro 1.

\section{Modelo Clássico}

O modelo clássico é o mais presente no Brasil desde a década de 1960, sendo baseado em cursos pontuais, comumente (e impropriamente) chamados de cursos de "reciclagem" ou de atualização, que são geralmente oferecidos pelas universidades ou pelas Secretarias de Educação. Como características gerais desse modelo, destacamos a separação entre teoria e prática desde o planejamento do curso até a execução, uma vez que esses cursos são planejados na academia - sem participação dos professores-alunos - e, posteriormente, as informações, conhecimentos ou técnicas são repassados a eles com o intuito de se atualizarem.

A concepção de ensino-aprendizagem característica desse modelo formativo é a de transmissão-recepção de informações com ênfase em uma metodologia de ensino rígida, com 
pouco ou nenhum foco no diálogo e no debate de ideias, com ênfase em instrumentos e recursos didáticos que pretensamente dariam eficácia ao ensino. Nessa concepção, são oferecidas propostas formativas, em geral, de curta duração, na forma de palestras, oficinas, seminários e, principalmente, cursos de capacitação ou treinamento, expressando uma visão tecnicista de formação, visto que instrumentalizam o professor para a aplicação de conteúdos em sala de aula (JACOBUCCI; JACOBUCCI; MEGID NETO, 2009).

\section{Modelo prático-reflexivo}

Contrariamente ao modelo clássico, em que há uma supremacia da teoria sobre a prática, no modelo prático-reflexivo as práticas docentes é que determinam quais teorias merecem ser observadas pelos professores, havendo uma valorização dos saberes experienciais. A concepção de ensino-aprendizagem subjacente a esse modelo é a construção do conhecimento pelos docentes a partir da reflexão sobre a sua prática profissional (antes, durante e/ou após a ação). Esse modelo tem como base a filosofia de Donald Schön inspirado principalmente em John Dewey (JACOBUCCI; JACOBUCCI; MEGID NETO, 2009).

De acordo com os autores supracitados, esse modelo parte do pressuposto de que os docentes elaboram novos conhecimentos a partir da reflexão sobre suas práticas, durante o ato educativo, em uma concepção interpretativa. O papel do formador é o de um mediador que incentiva a discussão sobre os problemas reais enfrentados pelos docentes por meio de atividades de reflexão sobre as práticas pedagógicas. Em geral, as propostas formativas estruturadas são oferecidas no formato de cursos de média a longa duração, ou de acompanhamento dos docentes pelo mediador, que podem proporcionar a transformação da prática pedagógica e da realidade escolar. Nessas propostas os professores podem ou não participar do planejamento das atividades em conjunto com a equipe técnica.

\section{Modelo emancipatório-político}

O modelo emancipatório-político tem como base a perspectiva sócio-histórica e a concepção crítico-dialética de formação de professores, em que o homem é visto como um ser social que necessita de uma sólida formação teórica para conseguir transformar, na prática, a realidade.

\footnotetext{
Diferentemente das propostas de Schön, em que o conhecimento gerado na prática é conseguido de forma individualizada, Carr e Kemmis, Elliott, Zeichner, Liston e McNiff, entre outros autores, acreditam que a atividade reflexiva exige uma relação dialética entre teoria e realidade, e percebem no ambiente colaborativo entre colegas professores e pesquisadores da universidade as condições institucionais e político-sociais necessárias para se refletir sobre a prática numa visão mais ampla de mundo (JACOBUCCI; JACOBUCCI; MEGID NETO, 2009, p. 121).
}

Nesta perspectiva, a pesquisa-ação é apontada como principal estratégia de emancipação dos docentes e transformação da realidade. As propostas são geralmente oferecidas na forma 
de projetos ou programas de longa duração, cujo planejamento e estruturação são feitos com a participação dos professores-alunos, que têm papel ativo durante todo o programa. Segundo os referidos autores, geralmente são constituídos grupos de trabalho que direcionam as propostas de atividades a serem realizadas durante o processo de formação, em que são discutidas a função da educação e o papel dos professores, as teorias educacionais, os problemas sociais e políticos e as diferentes práticas pedagógicas.

Quadro 1. Principais características dos modelos de formação de professores

\begin{tabular}{|l|l|l|l|}
\hline \multicolumn{1}{|c|}{ Características } & \multicolumn{1}{|c|}{ Clássico } & \multicolumn{1}{|c|}{ Prático-reflexivo } & \multicolumn{1}{|c|}{ Emancipatório-político } \\
\hline $\begin{array}{l}\text { Relação teoria/ } \\
\text { prática }\end{array}$ & Supremacia da teoria & Supremacia da prática & $\begin{array}{l}\text { Valorização equânime da } \\
\text { teoria e da prática, em } \\
\text { relação dialética }\end{array}$ \\
\hline $\begin{array}{l}\text { Papel do } \\
\text { formador }\end{array}$ & $\begin{array}{l}\text { Transmissor de } \\
\text { conteúdos }\end{array}$ & $\begin{array}{l}\text { Mediador que incentiva a } \\
\text { discussão sobre problemas } \\
\text { enfrentados pelos docentes }\end{array}$ & $\begin{array}{l}\text { Mediador e colaborador, } \\
\text { atuando em projetos } \\
\text { de colaboração entre } \\
\text { universidade e escola }\end{array}$ \\
\hline $\begin{array}{l}\text { Concepção de } \\
\text { Formação }\end{array}$ & Tecnicista & $\begin{array}{l}\text { Interpretativa, com base na } \\
\text { reflexão sobre a ação }\end{array}$ & $\begin{array}{l}\text { Perspectiva sócio-histórica e } \\
\text { crítico-dialética }\end{array}$ \\
\hline Exemplos & $\begin{array}{l}\text { Palestras, oficinas, } \\
\text { seminários, cursos } \\
\text { de capacitação ou } \\
\text { treinamento }\end{array}$ & $\begin{array}{l}\text { Cursos de média a } \\
\text { longa duração, ou de } \\
\text { acompanhamento dos } \\
\text { docentes pelo mediador }\end{array}$ & $\begin{array}{l}\text { Projetos de pesquisa-ação } \\
\text { desenvolvidos de forma } \\
\text { colaborativa }\end{array}$ \\
\hline
\end{tabular}

Fonte: Adaptado de Jacobucci (2006) e Jacobucci; Jacobucci; Megid Neto (2009).

Vale destacar, em consonância com Jacobucci (2006), que os referidos modelos constituem "recortes" dentre as várias categorizações que podem ser vislumbradas no campo da formação de professores no Brasil, os quais sofrem influência das concepções que os formadores e os próprios professores possuem sobre ensino. Nessa direção, apresentaremos, na próxima seção, a trajetória do Centro de Ciências da UFJF, contextualizando historicamente as experiências de formação continuada, foco de nossas reflexões neste artigo, para, a partir dela, analisar as concepções das propostas formativas.

\section{Caminhos metodológicos}

Esta pesquisa insere-se em uma perspectiva qualitativa (BOGDAN; BIKLEN, 1994). A análise dos dados foi realizada por Análise de Conteúdo (BARDIN, 2011; FRANCO, 2007), que tem como ponto de partida a mensagem, seja ela oral ou escrita, gestual, silenciosa, figurativa, documental ou diretamente provocada; expressando um significado e um sentido. Todos os documentos analisados na pesquisa, que compõem o corpus de análise, foram submetidos a intensas leituras e releituras, com o objetivo de encontrar sentidos, de formular e buscar respostas para a questão: quais as concepções formativas subjacentes às ações de formação continuada oferecidas pelo Centro de Ciências da UFJF? 
O corpus de análise foi constituído pelos projetos e relatórios submetidos e enviados à Fundação de Amparo à Pesquisa do Estado de Minas Gerais (FAPEMIG), à Coordenação de Aperfeiçoamento de Pessoal de Nível Superior (CAPES) e pelas pesquisas que tiveram tais experiências como objeto de investigação (PYRAMIDES, 2014; SILVA, P. R., 2014; SILVA, V. F., 2013; TAGLIATI et al., 2009).

As análises, desenvolvidas a partir do processo de categorização e inferência, foram realizadas com base nos modelos formativos sistematizados por Jacobucci (2006) e Jacobucci, Jacobucci e Megid Neto (2009) a partir dos trabalhos de Candau (1982, 1997), Damis (2003), Palma Filho e Alves (2003) e Pereira (2000), os quais foram considerados como categorias a priori, sendo suas características (sintetizadas no Quadro 1), tratadas como indicadores (BARDIN, 2011), dando-nos suporte para análise das ações formativas do Centro de Ciências da UFJF.

De acordo com Franco (2007) a categorização é uma operação de classificação de elementos constitutivos de um conjunto por diferenciação, seguida de um reagrupamento baseado em analogias a partir de critérios definidos. O processo de categorização consiste em várias leituras, tanto do corpus de análise, quanto de referenciais teóricos, buscando-se similaridades entre as informações, que levam à elaboração de categorias - denominadas categorias criadas a priori quando previamente estabelecidas. Tais categorias podem ser utilizadas em situações onde já se possui um padrão de dados bem estabelecido e se busca a comparação em outros contextos (FRANCO, 2007), como é o caso desta pesquisa que se vale das principais concepções e características dos modelos formativos.

\section{Reflexões sobre concepções e práticas formativas de experiências com a formação continuada de professores no Centro de Ciências da UFJF}

O Centro de Ciências da UFJF foi inaugurado em agosto de 2006 em um prédio anexo ao Colégio de Aplicação João XXIII da UFJF5 ${ }^{5}$, com a missão de propiciar aos estudantes, professores e ao público em geral, acesso ao conhecimento científico de forma lúdica e interativa. Assim, completou em 2016 seus dez anos de existência e militância.

Nos primeiros meses de funcionamento esse espaço não possuía equipamentos, mas contava com uma pequena equipe de professores voluntários e bolsistas dispostos a iniciar os trabalhos de popularização da Ciência. Assim, os equipamentos foram gradativamente sendo adquiridos por meio da submissão de projetos aos órgãos de fomento, de modo que, atualmente, a instituição dispõe de vários recursos, instalações e projetos, como: planetário inflável, tabela

\footnotetext{
${ }^{5} \mathrm{O}$ sucesso obtido tanto nas exposições, quanto nos eventos externos e cursos de formação continuada, levou a UFJF à criação de um novo espaço físico no Campus da UFJF, o qual foi inaugurado em 3 de julho de 2017 e que conta com um salão para exposições temporárias, uma Tabela Periódica Interativa, Espaço Aprenda Brincando, quatro laboratórios de Ciências, um planetário fixo digital com cúpula de 12 metros, um Observatório Espacial com telescópio fixo de 20 polegadas (além de outros 10 telescópios móveis, inclusive um solar) e as três exposições permanentes: A Célula ao Alcance da Mão, Espaço Interativo do Museu de Malacologia da UFJF e Museu de Arqueoastronomia e Etnologia Americana, o que o coloca como um dos maiores Centros de Educação Científica do Brasil (BASSOLI, 2017).
} 
periódica interativa, laboratórios de ciências, experimentos interativos de física, telescópio de alta resolução, exposição sobre o corpo humano, dentre outros recursos, que possibilitam o oferecimento de três roteiros de visitações ${ }^{6}$, eventos de cunho científico e ações de formação continuada de professores.

Dentre esses projetos, destacaremos o "Ciência Experimental na Escola", primeira experiência com a formação continuada de professores do Centro de Ciências que nasceu a partir de um projeto aprovado pela FAPEMIG no final de 2006, por meio do qual foi possível a aquisição de um conjunto completo de kits da Experimentoteca ${ }^{7}$. O referido projeto começou a ser oferecido em 2007, conforme descreveremos a seguir, tendo sofrido várias mudanças de concepção (e também de nome) até o ano de 2014, em que foi renomeado como "Novos Caminhos para o Ensino de Ciências" (Quadro 2).

\section{O projeto "Ciência Experimental na Escola"}

Na primeira experiência que ocorreu em 2007 e que envolveu professores de Ciências da Natureza atuantes no segundo segmento do Ensino Fundamental, as práticas formativas baseavam-se na utilização dos kits da Experimentoteca a partir de seus respectivos roteiros ${ }^{8}$. Segundo dados do relatório de atividades: "Durante o curso, os professores aprendem a trabalhar com cada um dos kits, e após cada encontro os kits ficam disponíveis para serem levados para a escola, permitindo ao professor trabalhar com atividades experimentais dentro da própria sala de aula" (UNIVERSIDADE FEDERAL DE JUIZ DE FORA, 2011, grifo nosso).

Podemos perceber nesse oferecimento, elementos da racionalidade técnica enquanto concepção formativa predominante, uma vez que se baseava no treinamento do professor, visto como um "técnico", para a aplicação das atividades experimentais nas escolas, conforme destacado no trecho a seguir:

Os professores treinados para usufruírem os kits de experiências fornecidas pela "Experimentoteca Pública" solicitam a reserva dos kits (do tópico de seu interesse), que assim são emprestados para as escolas para que os alunos possam utilizá-los em suas experiências, tudo a custo zero para as escolas públicas (UNIVERSIDADE FEDERAL DE JUIZ DE FORA, 2011, grifo nosso).

\footnotetext{
${ }^{6} \mathrm{O}$ roteiro 1 envolve duas atividades nos laboratórios, uma sessão no Planetário e acompanhamento no salão de experimentos interativos. O roteiro 2 envolve a visitação à Tabela Periódica Interativa com atividades na sala de vídeo, sala de Informática e laboratório de Química. O roteiro 3 envolve a visita à exposição "A célula ao alcance da mão".

${ }^{7}$ A Experimentoteca é formada por um conjunto de 40 kits produzidos pelo Centro de Divulgação Científica e Cultural (CDCC) da USP de São Carlos, que contém materiais que possibilitam a realização de atividades práticas envolvendo conteúdos de física, biologia, química e geociências, além de um roteiro para o professor e outro para os alunos.

${ }^{8}$ Disponível em: <http://www.cdcc.sc.usp.br/experimentoteca/fundamental.html>. Acesso em: 13 jan. 2017.
} 
Identificamos também, por meio dos elementos destacados acima, bem como pela curta duração do processo formativo (30 horas) e pelo papel desempenhado pelos formadores - papel de "treinadores" -, características típicas do modelo formativo clássico, em que o curso é planejado pelos "acadêmicos", por meio da utilização de roteiros de atividades experimentais produzidos por terceiros - no caso pelos professores da USP - sem a participação dos professores cursistas, desconsiderando-se suas vivências e saberes.

Tais características estão ainda muito presentes nos programas de formação continuada desenvolvidos no Brasil e também no exterior. Na pesquisa desenvolvida por Jacobucci, Jacobucci e Megid Neto (2009), os autores constataram que dentre os quatorze programas formativos analisados, seis têm características do modelo clássico, expressando uma visão tecnicista da formação ao focarem na instrumentalização do professor para a aplicação de conteúdos em sala de aula, valendo-se, frequentemente, de uma metodologia de ensino caracterizada pela transmissão-recepção de conhecimentos provenientes dos formadores, sendo o professor considerado simplesmente um aluno-receptivo, sem haver interação e troca de experiências entre as partes, além da ausência de discussões sobre a prática pedagógica e problemas escolares e sociais relacionados ao exercício da profissão, tornando a proposta pouco efetiva para uma formação mais autônoma dos docentes.

Em outra pesquisa que objetivou apresentar um panorama dos programas de formação continuada de professores em centros e museus de ciência da América Latina, Estados Unidos, Canadá, bem como de alguns países da Europa, Ásia e Oceania, Paula et al. (2014) verificaram que apenas dezenove dos setenta e nove espaços investigados disponibilizavam em seus sítios eletrônicos informações a respeito de atividades de formação continuada, havendo o predomínio de programas na modalidade oficinas e workshops, com atividades de curta duração, visando capacitar e atualizar os docentes em temas de ciências, o que os aproxima de um modelo formativo clássico.

\begin{abstract}
Os centros e museus de ciências que desenvolvem propostas de formação no modelo clássico reforçam um processo que está sendo abjurado pela [...] maioria dos pesquisadores em educação na atualidade. No entanto, a responsabilidade pelo oferecimento das propostas não é exclusiva desses espaços, pois a maioria dos programas é lançada com financiamento público de órgãos de fomento ou de secretarias de educação municipais e estaduais (JACOBUCCI; JACOBUCCI; MEGID NETO, 2009, p. 133).
\end{abstract}

Cabe destacar que o fato de classificarmos a experiência com o projeto "Ciência Experimental na Escola" como típica de um modelo formativo "clássico", não significa que ela não tenha contribuído para a formação dos professores, pois, conforme dados dos autores citados a seguir, o curso possibilitou mudanças na prática dos professores participantes:

Sobre a possível mudança de sua postura na sala de aula, os professores fazem declarações tais como: "Tenho agora a oportunidade de trazer para o cotidiano questões que por falta de recurso ficavam só na teoria"; “[...] está facilitando e me ajudando com novas ideias de aulas práticas”; [...] “Ao permitir a compreensão pela experimentação, isto acaba por ampliar nossa 
forma de interpretar fenômenos físicos o que melhora a nossa capacidade de educar". Em relação às reações dos alunos e sua evolução nas aulas de Física e de ciências, estes professores observaram o que se segue: "Os alunos participam e conseguem fundamentar melhor os conceitos teóricos. A aprendizagem se torna mais interessante" (TAGLIATI et al. 2009, p. 8).

Mediante esse quadro, esses autores refletem sobre os objetivos de tais atividades práticas, atentando para os riscos de se atribuir às atividades experimentais um fator preponderantemente motivacional, sem avaliação da aprendizagem dos estudantes. Como ressalta Tagliati et al. (2009, p. 9) " [...] o que desperta inicialmente um grande interesse na sala de aula pode cair numa espécie de frustração se as reações, sugestões e comportamento como um todo dos estudantes não for avaliada com critérios e parâmetros bem delineados".

Assim, cabe a nós indagar se não seria pertinente que essas reflexões fossem realizadas durante o processo formativo, possibilitando aos professores participarem ativamente e compartilharem suas expectativas e concepções, as quais poderiam ser problematizadas pelos formadores e postas em debate. Se o leitor considerar que esse é um caminho interessante do ponto de vista pedagógico, possivelmente concordaremos que, para tal, seria necessário abrir mão do modelo clássico, tendo sido esse o caminho trilhado no decorrer do percurso do Centro de Ciências, segundo nosso entendimento. Tagliati et al. (2009, p. 9) anteveem caminhos em que teoria, prática, ensino e pesquisa se confluem:

Isso nos leva a buscar ações integradas entre a prática na sala de aula, a investigação e valorização de aspectos pedagógicos de apoio ao estudante, e que devem ser enfatizadas nas atividades de formação continuada do professor, e o apoio possível em espaços não-formais, como num centro de ciências, por exemplo.

Embora, o curso tenha sido oferecido em 2008, no mesmo formato descrito acima, a partir de 2011 a proposta de formação continuada foi reelaborada, conforme apresentamos a seguir, tendo como público-alvo professores de Química, atuantes no Ensino Médio, sendo então renomeado como "O uso da experimentação no ensino de Química", objeto de investigação de Silva (2013).

\section{O projeto “O uso da experimentação no ensino de Química”}

Cabe destacar que esta versão do projeto, bem como as subsequentes, foram aprovadas e financiadas pela CAPES por meio do Programa Novos Talentos, tendo como principais objetivos:

- Criar condições para que os professores reflitam sobre o potencial e as limitações do uso da experimentação no ensino de química;

- Criar as condições para que os futuros professores desenvolvam material didático e estratégias inovadoras de forma crítica para o ensino de química (UNIVERSIDADE FEDERAL DE JUIZ DE FORA, 2010, grifos nossos). 
Ao analisarmos tais objetivos, percebemos um movimento de tentativa de rompimento com uma concepção de formação baseada em roteiros prontos, tipo "receita de bolo", cujo papel do professor restringe-se ao de um "técnico", uma vez que são enfatizados elementos como: reflexão, desenvolvimento de material didático e de estratégias inovadoras de forma crítica pelo professor. Esse movimento de rompimento com o modelo clássico também foi explicitado no projeto do curso, submetido à CAPES, conforme transcrito abaixo:

\begin{abstract}
Segundo Maldaner (2006), a formação continuada de professores consiste na maioria das vezes em propostas de curta duração visando uma "reciclagem" do professor. [...] Considerando a linha de pensamento proposta por Maldaner, no presente projeto desenvolveremos atividades de formação visando superar o modelo descrito voltado ao mero treinamento [...] (UNIVERSIDADE FEDERAL DE JUIZ DE FORA, 2010, grifos nossos).
\end{abstract}

Essa perspectiva da superação do modelo clássico foi indicada por Silva (2013, p. 114):

\begin{abstract}
A perspectiva dessa formação é criar condições para que o professor seja capaz de reelaborar esse material e reutilizar de acordo com as suas necessidades. Então, não poderia ser mais um curso em que o professor chegaria ao Centro de Ciências para receber uma atualização, no sentido que, muitas das vezes, é feita assim a formação continuada. Esse tipo de formação, que se baseia na reciclagem é um engano. Mas a intenção é levar em conta as reais necessidades e os interesses dos professores.
\end{abstract}

Assim, percebemos uma preocupação dos professores formadores, em propiciar uma formação continuada crítica e reflexiva, aproximando-se do modelo prático-reflexivo, partindo do pressuposto de que os docentes elaboram novos conhecimentos por meio da experiência prática e, que o professor é capaz de produzir conhecimentos a partir da reflexão sobre sua prática (JACOBUCCI; JACOBUCCI; MEGID NETO, 2009).

Nessa concepção de formação, segundo esses autores, há um foco maior nas práticas docentes do que nas teorias pedagógicas, entretanto, percebemos uma preocupação dos formadores em fornecer aos professores arcabouços teóricos para subsidiar as reflexões, conforme destacado abaixo a partir dos dados divulgados no relatório final do projeto?:

No curso, foi promovida inicialmente uma discussão teórica acerca das possibilidades da experimentação no ensino de química, através do uso de artigos científicos. Posteriormente, foram desenvolvidas atividades

\footnotetext{
${ }^{9}$ Foram selecionados artigos da revista Química Nova na Escola que abordam temas centrais do ensino de química, como, por exemplo, o artigo "Quanto mais quente melhor: calor e temperatura no ensino de termoquímica” (MORTIMER; AMARAL, 1998). As atividades experimentais foram elaboradas pelos professores e durante a sua execução eram realizadas discussões que possibilitavam sua reconstrução.
} 
experimentais no laboratório, que podem ser facilmente reproduzidas com os alunos nas escolas (UNIVERSIDADE FEDERAL DE JUIZ DE FORA, 2012, grifos nossos).

Ao investigar as impressões dos professores acerca do curso, Silva (2013) identificou certo grau de articulação entre teoria e prática, conforme destacado abaixo:

A metodologia usada nesse curso pode ser considerada como um fator importante para essa mudança de visão sobre o uso de experimentos, uma vez que o ensino prático realizado através da experimentação interagiu com os textos abordados (do Caderno de Textos), durante todo o desenvolvimento das aulas (SILVA, 2013, p. 163, grifos nossos).

É importante destacar que nesta versão do projeto a relação dos professores com os kits foi diferente da versão anterior, visto que eles já não se encontravam prontos para o professor, bem como seus roteiros de utilização, conforme descrito por Silva (2013, p. 176):

Os kits não são padronizados e nem possuem um roteiro predeterminado, mas são montados de acordo com a solicitação do professor para atenderem às suas demandas específicas quanto ao experimento que realizará na escola. [...] O enfoque foi colocado na autonomia do professor em planejar a sua aula prática e solicitar ao Centro [de Ciências] o material e/ou orientação sobre o experimento.

Nesse sentido, também percebemos nos depoimentos dos professores, trazidos por Silva (2013), uma mudança no papel dos professores formadores, não mais “treinadores”, mas, mediadores ou "assessores" no processo de formação docente.

Além disso, esse tipo de assessoria pode ser observado em relação ao estímulo à reflexão sobre a prática, que foi outro aspecto apresentado pelos professores cursistas como um diferencial desse curso do Centro de Ciências, uma vez que os docentes foram desafiados a pensarem sobre o processo ensino e aprendizagem, refletindo sobre as suas aulas, tanto na fase de elaboração quanto na de execução [...] (SILVA, 2013, p. 183).

Segundo a autora, a partir dos relatos dos sujeitos dessa pesquisa foi possível considerar que o processo formativo em questão favoreceu o raciocínio pedagógico, ao trabalhar a formação docente na perspectiva da reflexão crítica, da construção do conhecimento e da relação teoria e prática como eixos estruturantes desse processo.

Para finalizar a análise dessa versão do projeto, cabe destacar a ampliação da carga horária de 30 para 40 horas em relação às versões anteriores, tendo em vista a necessidade de um maior tempo para a discussão sobre os problemas enfrentados pelos docentes, mediada pelos professores formadores. Mesmo com essa ampliação, os docentes ainda consideraram a carga horária reduzida, de modo que: 


\begin{abstract}
Os professores aludiram ao desejo de continuidade para a abordagem de outros conteúdos e experimentos, com o propósito de estenderem esse processo de formação continuada, justamente por perceberem seu valor e significado para o desenvolvimento profissional docente (SILVA, 2013, p. 189).
\end{abstract}

Dessa forma, a partir da análise dos aspectos apontados acima, referentes à experiência desenvolvida em 2011, podemos inferir que a mesma apresenta características do modelo prático-reflexivo, embora não exclusivamente, tendo em vista a existência de "matizes" entre os diferentes modelos de formação.

Na pesquisa desenvolvida por Jacobucci, Jacobucci e Megid Neto (2009), dos quatorze programas investigados, seis se enquadraram no modelo prático-reflexivo, focando na confecção de kits didáticos, em conteúdos e metodologias de ensino, com ênfase na experimentação, valorizando-se a reflexão sobre as práticas - pontos de partida para o início das atividades de formação. De acordo com os autores, os docentes são considerados participantes ativos no processo de formação, a discussão dos problemas educacionais é mediada pela equipe técnica dos centros e museus de ciências e há incentivo para a mudança da prática pedagógica via reflexão contínua sobre o trabalho docente. Nesse sentido, apontam o potencial desses programas, visto que "podem se transformar em pontes para um trabalho mais amplo e sólido na formação de professores, se passarem a inserir elementos históricos, políticos, sociais e culturais" (JACOBUCCI; JACOBUCCI; MEGID NETO, 2009, p. 131).

\title{
O projeto "Ciência Experimental na Escola": uma nova versão
}

Devido à prorrogação do projeto pela CAPES, a proposta formativa anteriormente descrita foi realizada novamente no segundo semestre de 2012, entretanto, o público-alvo foram os professores de ciências da natureza atuantes no segundo segmento do ensino fundamental, de modo que o foco da proposta deslocou-se da química para uma perspectiva mais interdisciplinar, envolvendo discussões sobre conteúdos de física, química, biologia e geologia, bem como a elaboração de experimentos com esses conteúdos. Assim, as discussões de cunho epistemológico sobre o papel da experimentação foram mantidas, agregando-se a elas discussões sobre interdisciplinaridade. Considerando que as concepções que nortearam a versão anterior mantiveram-se inalteradas, inclusive a carga horária, inferimos que essa experiência apresenta as mesmas características destacadas anteriormente.

\section{O projeto "Novos Caminhos para o Ensino de Ciências"}

O projeto de formação continuada, denominado "Novos caminhos para o ensino de ciências", também foi financiado pela CAPES por meio do Programa Novos Talentos e iniciouse em março de 2014, tendo como foco os professores de ciências da rede pública de ensino, atuantes no segundo segmento do Ensino Fundamental.

Nesta experiência houve um redirecionamento em relação às versões anteriores, uma vez que se buscou, intencionalmente, aproximá-la do modelo formativo emancipatório-político (BASSOLI, 2017). Comparando-a com as versões anteriores, a carga horária do curso foi 
ampliada para 100 horas, o número de vagas oferecidas foi reduzido de 25 para 7 vagas, tendo sido preenchidas 4, utilizando-se como estratégias formativas a pesquisa-ação colaborativa (IBIAPINA, 2008) e os ciclos de reflexão crítica sobre a prática (SMYTH, 1992).

Tal mudança pautou-se pela necessidade, observada pelos formadores, de se favorecer transformações mais efetivas nas concepções e na prática docente, conforme verificado por Pyramides (2014) ao analisar as concepções dos participantes do curso "Ciência Experimental na Escola", no segundo semestre de 2012:

Acreditamos que o curso de formação continuada, no modelo inicialmente
proposto, não foi suficiente para aprofundar esta discussão acerca dos
temas discutidos nesta pesquisa nas etapas I e II. Contudo, consideramos
que a etapa II desta pesquisa foi importante, no sentido de aprofundar a
problematização das diversas questões que nos dispomos a debater (PYRA-
MIDES, 2014, p. 101).

Cabe destacar que a etapa II da pesquisa de Pyramides (2014), segundo Ibiapina (2008), consistiu na realização de ciclos de reflexão crítica sobre a prática docente por meio do "ciclo de Smyth" (SMYTH, 1992), a partir da análise de gravações das aulas dos professores participantes. Desse modo, tais reflexões influenciaram a concepção da proposta formativa desenvolvida nos anos de 2014 e 2015, a qual teve como principais objetivos:

- Proporcionar aos professores uma aproximação às pesquisas em edu-
cação em Ciências, a fim de não somente conhecer os resultados de tais
pesquisas, como também a atuarem como pesquisadores;
- Contribuir para a formação docente em uma perspectiva reflexiva, capaz de
instrumentalizar o professor a produzir conhecimentos no e sobre o ensino;
- Possibilitar aos professores uma oportunidade de se verem como autores
de um processo de inovação curricular e de poderem socializar tal expe-
riência através da produção de um livro (UNIVERSIDADE FEDERAL
DE JUIZ DE FORA, 2013, grifos nossos).

É importante destacar que embora o processo formativo tenha sido planejado contemplando as etapas apresentadas no Quadro 2, estas não tinham nem uma duração pré -estabelecida, nem um roteiro prévio, de forma a valorizar as demandas do grupo e a tomada coletiva de decisões, considerando-se, contudo, as etapas subsequentes.

A reflexão crítica sobre a própria prática, eixo central da proposta formativa, pode ser percebida em diversos momentos do processo e, em especial, nas produções textuais das professoras, conforme exemplificado no texto de Flávia (nome fictício) reproduzido abaixo:

Estas gravações em vídeo, além da utilização do ciclo de Smyth, revelaram-se como poderosas ferramentas de análise da minha própria prática, possibilitando-me tomar consciência de algumas características da minha aula que não me eram transparentes, tais como: falta de planejamento - questão que surgiu antes e emergiu com as gravações -, falta de "espaço" para o aluno expressar suas opiniōes e ser participativo, bem como 
a necessidade de assumir um papel de "mediadora" do conbecimento e não somente de transmissora.

Quadro 2. Etapas do processo formativo "Novos Caminhos para o Ensino de Ciências"

\begin{tabular}{|l|l|}
\hline Etapa/duração & Ações desenvolvidas \\
\hline $1^{a}$ Etapa -6 encontros & $\begin{array}{l}\text { Aproximações entre os professores e os referencias teóricos: discussão de } \\
\text { artigos científicos }\end{array}$ \\
\hline $2^{\mathrm{a}}$ Etapa -7 encontros & Elaboração de um projeto ou sequência de ensino/pesquisa \\
\hline $3^{\mathrm{a}}$ Etapa -7 encontros & Desenvolvimento das sequências de ensino ${ }^{10}$ e filmagem das aulas \\
\hline $4^{\mathrm{a}}$ Etapa -4 encontros & Análise reflexiva das aulas (SMYTH, 1991; IBIAPINA, 2008) \\
\hline $5^{\mathrm{a}}$ Etapa -3 encontros & $\begin{array}{l}\text { Compartilhando os conhecimentos: participação em congressos, } \\
\text { elaboração de relatos de experiência e de capítulos de livro }\end{array}$ \\
\hline
\end{tabular}

Fonte: Elaborado pelos autores.

As pesquisas desenvolvidas sobre esta experiência têm indicado contribuições para o desenvolvimento profissional dos professores participantes, tais como: reflexão crítica sobre a formação e a prática docente, aproximação às pesquisas e produção de conhecimentos sobre o ensino, consolidadas com a elaboração e apresentação de trabalhos em congresso; e, a produção de capítulos de livro pelos pelos docentes (BASSOLI; LOPES; CESAR, 2015; BASSOLI, 2017).

De acordo com Jacobucci, Jacobucci e Megid Neto (2009) os programas fundamentados no modelo emancipatório-político são pouco frequentes, sendo verificados apenas dois dentre os quatorze analisados em sua pesquisa, os quais enfocam a mudança da realidade social e escolar, a partir de questões socioambientais, o que favorece a flexibilização do ensino de ciências e a modificação do currículo escolar e, principalmente amplia a visão de mundo dos professores, encorajando-os a "transitar no campo da ação política, democrática e cidadã para a transformação da realidade que vivenciam" (JACOBUCCI; JACOBUCCI; MEGID NETO, 2009, p. 132). É apostando nesta perspectiva que o Centro de Ciências da UFJF, por meio de sua equipe de colaboradores, tem buscado o aprimoramento das propostas de formação continuada de professores.

\section{Considerações finais}

A partir das análises aqui empreendidas sobre as experiências de formação continuada de professores de Ciências da Natureza e Química foi possível encontrar elementos que refletem mudanças na concepção - inicialmente pautados na racionalidade técnica (modelo clássico),

\footnotetext{
${ }^{10}$ Foram utilizados os seguintes critérios para a definição das temáticas das sequências de ensino: É um tema de natureza controvertida? O tema tem relevância social? Em alguma dimensão, é relativo à ciência-tecnologia? Assim, os temas das sequências elaboradas pelos diferentes professores com o apoio do grupo foram: drogas, água e educação ambiental.
} 
Reflexões sobre experiências de formação continuada de professores ...

posteriormente no modelo prático-reflexivo e, mais recentemente, no modelo emancipatório -político. Sobre tais mudanças de "percurso", é importante destacar que visaram os objetivos da instituição no que diz respeito à sua contribuição para a formação continuada de professores, bem como, a investigação de questões relacionadas à educação científica e ao desenvolvimento de inovações, recursos e materiais pedagógicos para o ensino das ciências nas escolas de educação básica, com o potencial de contribuir para a área de Educação em Ciências, especialmente no que tange a formação de professores.

Nessa direção, as pesquisas desenvolvidas sobre essas diferentes experiências formativas, aliadas às reflexões dos professores formadores sobre as práticas pedagógicas com o suporte de referenciais teóricos, tiveram um papel central nas mudanças implementadas, podendo fornecer subsídios para outros trabalhos na área. Por fim, destacamos a importância de pesquisas que busquem avaliar a articulação teórico-prática dos programas de formação continuada de professores, priorizando as demandas dos docentes em sintonia com os resultados das pesquisas educacionais. Nesse sentido, compreendemos que a análise e a socialização desses processos é a principal contribuição deste trabalho para a área.

\section{Agradecimentos}

À Coordenadoria de Aperfeiçoamento de Pessoal de Nível Superior (CAPES), Conselho Nacional de Desenvolvimento Científico e Tecnológico (CNPq) e à Fundação de Amparo à Pesquisa do Estado de Minas Gerais (FAPEMIG) pelo financiamento dos projetos que permitiram a realização das experiências formativas, ao Centro de Ciências da UFJF e aos professores participantes.

Este trabalho é um projeto de pesquisa colaborativa desenvolvida entre membros da Rede Mineira de Química (RQ-MG) financiado pela FAPEMIG (Projeto CEX - RED-0010-14).

\section{Referências}

ALARCÃO, I. Professores reflexivos em uma escola reflexiva. 8. ed. São Paulo: Cortez, 2011.

AZEVEDO, R. O. M. et al. Formação inicial de professores da educação básica no Brasil: trajetória e perspectivas. Diálogo Educacional, Curitiba, v. 12, n. 37, p. 997-1026, 2012.

BARDIN, L. Análise de conteúdo. São Paulo: Edições 70, 2011.

BASSOLI, F. Desenvolvimento Profissional Docente: Contribuições e Limites de um processo formativo em um grupo colaborativo de professores de Ciências da rede pública de Juiz de Fora (MG). 2017. 281f. Tese. (Doutorado em Química) - Universidade Federal de Juiz de Fora, Juiz de Fora, 2017.

BASSOLI, F.; LOPES, J. G. S.; CESAR, E. T. (Org.). Contribuições de um centro de ciências para a formação continuada de professores: percursos formativos, parcerias, reflexões e pesquisas. São Paulo: Livraria da Física, 2015. 
BIZERRA, A. F. Atividade de aprendizagem em museus de ciências. 2009. 274 f. Tese (Doutorado em Educação) - Faculdade de Educação, Universidade de São Paulo, São Paulo, 2009.

BOGDAN, R.; BIKLEN, S. Investigação qualitativa em educação: uma introdução à teoria e aos métodos. Porto: Porto Editora, 1994.

CANDAU, V. M. F. Formação continuada de professores: tendências atuais. In: (Ed.). Magistério: construção cotidiana. Petrópolis: Vozes, 1997. p. 51-68.

. A formação de educadores: uma perspectiva multidimensional. Em Aberto, Brasília, v. 1, n. 8, p. 19-21, 1982.

CUNHA, M. I. O tema da formação de professores: trajetórias e tendências do campo na pesquisa e na ação. Educação e Pesquisa, São Paulo, n. 3, p. 609-625, jul./set. 2013.

DAMIS, O. T. Formação pedagógica do profissional da educação no Brasil: uma perspectiva de análise. In: VEIGA, I. P. A.; AMARAL, A. L. (Org.). Formação de professores: políticas e debates. Campinas: Papirus, 2003. p. 97-130.

DINIZ-PEREIRA, J. E.; ZEICHNER, K. M. (Org.). A pesquisa na formação e no trabalho docente. 2. ed. Belo Horizonte: Autêntica, 2011.

ELLIOT, J. La investigación-acción em educación. 6. ed. Madrid: Morata, 2010.

FRANCO, M. L. P. B. Análise de conteúdo. 2. ed. Brasília: Liber Livro, 2007.

GATTI, B. Formação de professores: condições e problemas atuais. Revista Brasileira de Formação de Professores, Cristalina, v. 1, n. 1., p. 90-102, 2009. Disponível em: <https:// tinyurl.com/ycw5sx4u>. Acesso em 22 set. 2017.

GOUVÊA, G. et al. Redes cotidianas de conhecimentos e os museus de ciências. Parcerias Estratégicas, Brasília, v. 6, n. 11, 169-174, 2001. Disponível em: < http://seer.cgee.org.br/ index.php/parcerias_estrategicas/article/viewFile/167/161>. Acesso em 22 set. 2017.

IBIAPINA, I. M. L. M. Pesquisa colaborativa: investigação, formação e produção de conhecimentos. Brasília: Liber Livro, 2008.

JACOBUCCI, D. F. C. A formação continuada de professores em centros e museus de ciências no Brasil. 2006. 302 f. Tese (Doutorado em educação) - Faculdade de Educação, Universidade Estadual de Campinas, Campinas, 2006.

JACOBUCCI, D. F. C.; JACOBUCCI, G. B.; MEGID NETO, J. Experiências de formação de professores em centros e museus de ciências no Brasil. Revista Electrónica de Enseñanza de las Ciencias, Vigo, v. 8, n. 1, p. 118-136, 2009. Disponível em: <http://reec.uvigo.es/ volumenes/volumen8/ART7_Vol8_N1.pdf>. Acesso em: 22 set. 2017.

KEMMIS, S.; WILKINSON, M. A pesquisa-ação participativa e o estudo da prática. In: DINIZ-PEREIRA, J. E.; ZEICHNER, K. M. (Org.). A pesquisa na formação e no trabalho docente. 2. ed. Belo Horizonte: Autêntica, 2011. p. 39-60. 
Reflexões sobre experiências de formação continuada de professores ...

MALDANER, O. A. A formação inicial e continuada de professores de química: professores/pesquisadores. 3. ed. Ijuí: Ed. Unijuí, 2006.

MARCELO, C. Formação de professores para uma mudança educativa. Porto: Porto Editora, 1999.

MORTIMER, E. F.; AMARAL, L. O. F. Quanto mais quente melhor: calor e temperatura no ensino de termoquímica. Química Nova na Escola, São Paulo, n. 7, p. 30-34,1998. Disponível em: <http://qnesc.sbq.org.br/online/qnesc07/aluno.pdf>. Acesso em: 22 set. 2017.

NÓVOA, A. (Org.). Vidas de professores. 2. ed. Porto: Porto Editora, 2007.

OLIVEIRA, R. L. Formação docente: traçando modelos que subjazem à prática. Quipus, Natal, v. 1, n. 1, p. 13-24, 2011. Disponível em: <https://repositorio.unp.br/index.php/ quipus/article/view/53/101 >. Acesso em: 22 set. 2017.

OVIGLI, D. F. B. As pesquisas sobre educação em museus e centros de ciências no Brasil: estudo descritivo e analítico da produção acadêmica. 2013. 404 f. Tese (Doutorado em Educação para a Ciência) - Faculdade de Ciências, Universidade Estadual Paulista, Bauru, 2013.

PAULA, L. M. et al. Formação continuada de professores em centros e museus de ciências: um olhar acerca dos programas oferecidos nestes espaços. Latin American Journal of Science Education, Mexico, v. 1, n. 1, p. 13016-1/13016-11, 2014.

PALMA FILHO, J. C.; ALVES, M. L. Formação continuada: memórias. In: BARBOSA, R. L. L. (Ed.). Formação de educadores: desafios e perspectivas. São Paulo: Ed. Unesp, 2003. p. 279-296.

PEREIRA, G. R. O ensino de ciências nos anos iniciais do ensino fundamental e a formação continuada de professores: implantação e avaliação do programa formativo de um centro de ciência. 2014. 231 f. Tese (Doutorado em Ciências Biológicas) - Universidade Federal do Rio de Janeiro, Rio de Janeiro, 2014.

PEREIRA, J. E. D. Formação de professores: pesquisa, representações e poder. Belo Horizonte: Autêntica, 2000.

PIMENTA, S. G. Pesquisa-ação crítico-colaborativa: construindo seu significado a partir de experiências com a formação Docente. Educação e Pesquisa, São Paulo, v. 31, n. 3, p. 521-539, 2005. Disponível em: <http://dx.doi.org/10.1590/S1517-97022005000300013>. Acesso em: 22 set. 2017.

PYRÂMIDES, C. M. M. Formação continuada de professores de química e o ensino experimental na perspectiva do professor reflexivo. 2014. 128 f. Dissertação (Mestrado em Educação Química) - Universidade Federal de Juiz de Fora, Juiz de Fora, 2014.

SAVIANI, D. Formação de professores: aspectos históricos e teóricos do problema no contexto brasileiro. Revista Brasileira de Educação, Rio de Janeiro, v. 14 n. 40, p. 143-155, 2009. Disponível em: <http://dx.doi.org/10.1590/S1413-24782009000100012>. Acesso em: 22 set. 2017. 
SHULMAN, L. S. Those who understand: knowledge growth in teaching. Educational Researcher, Thousand Oaks, v. 15, n. 2, p. 4-14, 1986.

SILVA, P. R. Um estudo sobre os desafios para a atuação docente na disciplina ciências do sexto ao nono ano do ensino fundamental. 2014. 126 f. Dissertação (Mestrado em Educação Química) - Universidade Federal de Juiz de Fora, Juiz de Fora, 2014.

SILVA, V. F. Formação docente \& centro de ciências: estudo sobre uma experiência de formação continuada de professores de química. 2013. 220 f. Tese (Doutorado em Educação para a Ciência) - Faculdade de Ciências, Universidade Estadual Paulista, Bauru, 2013.

SILVA, V. F.; BASTOS, F. Formação de professores de ciências: reflexões sobre a formação continuada. Alexandria: revista de educação em ciência e tecnologia, Florianópolis, v. 5, n. 2, p. 150-188, 2012.

SMYTH, J. Una pedagogía crítica de la práctica en el aula. Revista de Educación, Madrid, n. 294, p. 275-300, 1991.

TAGLIATI, J. R. et al. Atividades de formação continuada do professor: o olhar num centro de ciências. In: SIMPÓSIO NACIONAL DE ENSINO DE FÍSICA, 18., Vitória, 2009.

Atas... Disponível em: <http://www.sbf1.sbfisica.org.br/eventos/snef/xviii/sys/resumos/ T0389-1.pdf>. Acesso em: 22 set. 2017.

TARDIF, M. Saberes docentes e formação profissional. 10. ed. Petrópolis: Vozes, 2010. UNIVERSIDADE FEDERAL DE JUIZ DE FORA. Centro de Ciências. Novos caminhos para o ensino de ciências na escola. [Juiz de Fora]: Universidade Federal de Juiz de Fora, 2010. (Programa Novos Talentos).

Novos caminhos para o ensino de ciências na escola: relatório de atividades. [Juiz de Fora]: UFJF, 2011. (Programa Novos Talentos).

. Novos caminhos para o ensino de ciências na escola: relatório de atividades. [Juiz de Fora]: UFJF, 2012. (Programa Novos Talentos).

Novos caminhos para o ensino de ciências na escola. [Juiz de Fora]:

Universidade Federal de Juiz de Fora, 2013. (Programa Novos Talentos).

ZEICHNER, K. M. A. Formação reflexiva de professores: ideias e práticas. Lisboa: Educa, 1993.

Artigo recebido em 11/08/2016. Aceito em 02/02/2017.

Endereço para contato: Universidade Federal de Juiz de Fora, Ciências Naturais, Rua Visconde de Mauá, 300, Santa Catarina, CEP 36052-530, Juiz de Fora, MG, Brasil. 